\title{
Article
}

\section{DNA-Gold Nanorod Conjugates for Remote Control of Localized Gene Expression by near Infrared Irradiation}

Chia-Chun Chen, Yen-Ping Lin, Chih-Wei Wang, Hsiao-Chien Tzeng, Chia-Hsuan

Wu, Yi-Cheng Chen, Chin-Pei Chen, Li-Chyong Chen, and Yi-Chun Wu

J. Am. Chem. Soc., 2006, 128 (11), 3709-3715• DOI: 10.1021/ja0570180 • Publication Date (Web): 24 February 2006

Downloaded from http://pubs.acs.org on May 16, 2009
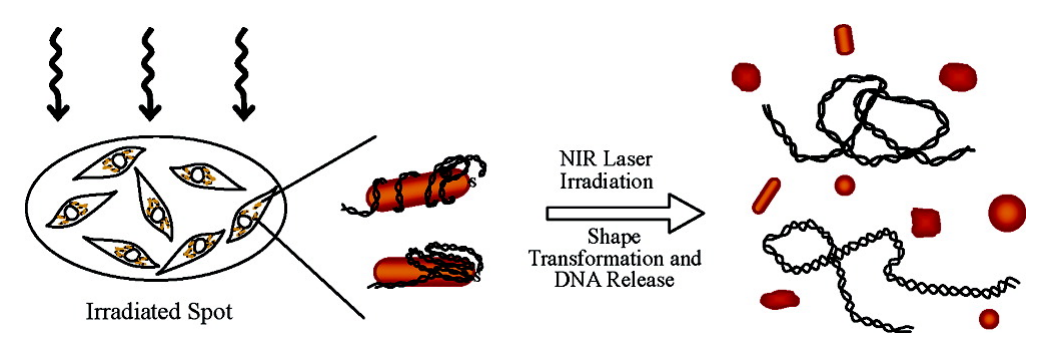

\section{More About This Article}

Additional resources and features associated with this article are available within the HTML version:

- Supporting Information

- $\quad$ Links to the 29 articles that cite this article, as of the time of this article download

- $\quad$ Access to high resolution figures

- $\quad$ Links to articles and content related to this article

- $\quad$ Copyright permission to reproduce figures and/or text from this article

\section{View the Full Text HTML}




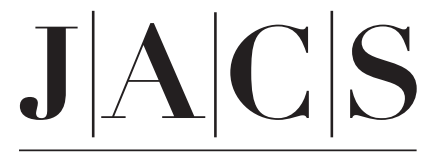

A R T I C L E S

Published on Web 02/24/2006

\title{
DNA-Gold Nanorod Conjugates for Remote Control of Localized Gene Expression by near Infrared Irradiation
}

\author{
Chia-Chun Chen, ${ }^{*,+, \neq}$ Yen-Ping Lin, ${ }^{\dagger}$ Chih-Wei Wang, ${ }^{\dagger}$ Hsiao-Chien Tzeng, ${ }^{\dagger}$ \\ Chia-Hsuan Wu, ${ }^{\dagger}$ Yi-Cheng Chen, ${ }^{\dagger}$ Chin-Pei Chen, ${ }^{\S}$ Li-Chyong Chen,,${ }^{\circledR}$ and \\ Yi-Chun $\mathrm{Wu}^{\perp, *}$ \\ Contribution from the Departments of Chemistry, National Taiwan Normal University, \\ Taipei 116, Taiwan, Institute of Atomic and Molecular Sciences, Academia Sinica, Taipei 106, \\ Taiwan, Center for Condensed Matter Science, and Institute of Molecular and Cellular Biology, \\ National Taiwan University, Taipei 106, Taiwan
}

Received October 14, 2005; E-mail: cjchen@ntnu.edu.tw; yichun@ntu.edu.tw.

\begin{abstract}
Gold nanorods were attached to the gene of enhanced green fluorescence protein (EGFP) for the remote control of gene expression in living cells. The UV-vis spectroscopy, electrophoresis, and transmission electron microscopy (TEM) were used to study the optical and structural properties of the EGFP DNA and gold nanorod (EGFP-GNR) conjugates before and after femto-second near-infrared (NIR) laser irradiation. Upon NIR irradiation, the gold nanorods of EGFP-GNR conjugates underwent shape transformation that resulted in the release of EGFP DNA. When EGFP-GNR conjugates were delivered to cultured HeLa cells, induced GFP expression was specifically observed in cells that were locally exposed to NIR irradiation. Our results demonstrate the feasibility of using gold nanorods and NIR irradiation as means of remote control of gene expression in specific cells. This approach has potential applications in biological and medical studies.
\end{abstract}

The applications of nanomaterials as probes and carriers in biological systems have recently attracted great interest. ${ }^{1}$ Metal, semiconductor, and insulator nanomaterials such as nanoparticles, nanorods, and nanotubes have been conjugated with different types of bio-molecules to be developed into new types of biological probes and carriers. ${ }^{2}$ Comparison to conventional labeling and delivery methods, the strategies using biomolecule and nanomaterial conjugates have several advantages. In particular, due to the unique optical and structural properties of some nanomaterials, their applications as stable fluorescent labelers ${ }^{3}$ or nonviral gene carriers ${ }^{4}$ have been explored. For example, fluorescent semiconductor nanoparticles (quantum dots) have been widely used as selective fluorescent biological

\footnotetext{
Department of Chemistry, National Taiwan Normal University.

$\doteqdot$ Institute of Atomic and Molecular Sciences, Academia Sinica.

$\S$ Center for Condensed Matter Science, National Taiwan University.

${ }^{\perp}$ Institute of Molecular and Cellular Biology, National Taiwan University.

(1) For a recent review, see: (a) Alivisatos, A. P. Nat. Biotechnol. 2004, 22 47-52. (b) Rosi, N. L.; Mirkin, C. A. Chem. Rev. 2005, 105, 1547-1562. (c) Katz, E.; Willner, I. Angew. Chem., Int. Ed. 2004, 43, 6042-6108. (d) Daniel, M.-C.; Astruc, D. Chem. Rev. 2004, 104, 293-346. (e) Niemeyer, C. M. Angew. Chem., Int. Ed. 2001, 40, 4128-4158. (f) Pellegrino, T. Kudera, S.; Liedl, T.; Javier, A. M.; Manna, L.; Parak, W. J. Small 2005. $1,48-63$.

(2) (a) Thomas, M.;Klibanov, A. M. Proc. Natl. Acad. Sci. U.S.A. 2003, 100, 9138-9143. (b) Salem, A. K.; Searson, P. C.; Leong, K. W. Nat. Mater. 2003, 2, 668-671. (c) Martin, C. R.; Kohli, P. Nat. Rev. Drug Discovery 2003, 2, 29-37. (d) Kam, N. W. S.; Jessop, T. C.; Wender, P. A.; Dai, H. J. Am. Chem. Soc. 2004, 126, 6850-6851. (e) Kam, N. W. S.; Liu, Z.; Dai, H. J. Am. Chem. Soc. 2005, 127, 12492-12493. (f) West, J.; Halas, N. Curr. Opin. Biotechnol. 2000, 11, 215-217. (g) Yoon, T. J.; Kim, J. S.; Kim, B. G.; Yu, K. N.; Cho, M. H.; Lee, J. K. Angew. Chem., Int. Ed. 2005, 44, 1068-1071. (h) Tsai, C. Y.; Shiau, A. L.; Cheng, P. C.; Shieh D. B.; Chen, D. H.; Chou, C. H.; Yeh, C. S.; Wu, C. L. Nano lett. 2004, 4, 1209-1212.
}

labels for the studies of specific biological processes in cells and tissues and have even been demonstrated under in vivo conditions. ${ }^{3}$ Furthermore, multivalent carbohydrate gold nanoparticles have been applied to identify specific protein localized in the bacterial pili. ${ }^{5}$ In addition to biolabeling, conjugates of biomolecules and gold nanoparticles (or nanorods) have been demonstrated and applied in biomolecule delivery and detection systems. ${ }^{2 a, b, 4}$ Besides gold nanomaterials, carbon nanotubes ${ }^{6}$ and fluorescent silica nanotubes ${ }^{7}$ have been utilized to deliver functional proteins and genes into cells, respectively.

(3) (a) Bruchez, M.; Moronne, M.; Gin, P.; Weiss, S.; Alivisatos, A. P. Science 1998, 281, 2013-2016. (b) Chan, W. C. W.; Nie, S. Science 1998, 281, 2016-2018. (c) Wu, M. X., Liu, H.; Liu, J.; Haley, K. N.; Treadway, J. A.; Larson, J. P.; Ge, N.; Peale, F.; Bruchez, M. P. Nat. Biotechnol. 2003, 21, 41-46. (d) Dubertret, B.; Skourides, P.; Norris, D. J.; Noireauz, V.; Brivanlou, A. H.; Libchaber, A. Science 2002, 298, 1759-1762. (e) Jaiwal, J. K.; Mattoussi, H.; Mauro, J. M.; Simon, S. M. Nat. Biotechnol. 2003 $21,47-51$

(4) (a) Yamada, T.; Iwasaki, Y.; Tada, H.; Iwabuki, H.; Chuah, M. KL.; VandenDriessche, T.; Fukuda, H.; Konodo, A.; Ueda, M.; Seno, M.; Tanizawa, K.; Kuroda, S. Nat. Biotechnol. 2003, 21, 885-890. (b) Suillvan, M. M. O.; Green, J. J.; Przybcien, T. M. Gene Therapy 2003, 10, 18821890. (c) Sudeep, P. K.; Joseph, S. T. S.; Thomas, K. G. J. Am. Chem. Soc. 2005, 127, 6516-6517. (d) Casewell, K. K.; Wilson, J. N.; Bunz, U. H. F.; Murphy, C. J. J. Am. Chem. Soc. 2003, 125, 13914-13915. (e) Liao, H.; Hafner, J. H. Chem. Mater. 2005, 17, 4636-4641. (f) Dujardin, E.; Hsin, L. B.; Wang, C. R. C.; Mann, S. Chem. Commun. 2001, 12641265 .

(5) (a) Lin, C.-C.; Yeh, Y.-C.; Yang, C.-Y.; Chen, C.-L.; Chen, G.-F.; Chen, C.-C.; Wu, Y.-C. J. Am. Chem. Soc. 2002, 124, 3508-3509. (b) Lin, C.C.; Yeh, Y.-C.; Yang, C.-Y.; Chen, G.-F.; Chen, Y.-C.; Wu, Y.-C.; Chen, C.-C. Chem. Commun 2003, 2920-2921.

(6) (a) Kam, N. W. S.; Dai, H. J. Am. Chem. Soc. 2005, 127, 6021-6026. (b) Kam, N. W. S.; O'Connell, M.; Wisdom, J. A.; Dai, H. Proc. Natl. Acad. Sci. U.S.A. 2005, 102, 11600-11605

(7) Chen, C.-C.; Liu, Y.-C.; Wu, C.-H.; Yeh, C.-C.; Su, M.-T.; Wu, Y.-C. Adv. Mater. 2005, 17, 404-407. 
Recently, research efforts have been focused on developing inducible systems to control the biological activities of bionanomaterial conjugates in cultured mammalian cells by applied electronic, optical, ultrasonic, or magnetic signals. For example, remote control of DNA hybridization was achieved through inductive coupling by applying a radio frequency magnetic field to a gold nanoparticle covalently linked to DNA. ${ }^{8}$ Metal nanoshells conjugated with thiolated polymers have been applied for near-infrared (NIR) thermal therapy of tumors under magnetic resonance guidance. ${ }^{9}$ Optically responsive capsules of gold nanoparticles incorporated within polyelectrolyte multilayer shell were used to release encapsulated biomaterials by laser irradiation. ${ }^{10}$ In these examples, the nanomaterials were served not only as a bio-molecule carrier but also as switching devices in combination with external optical or magnetic signals.

Triggering of biological activity using photon irradiation is a relatively simple technique to execute in cells and organisms. ${ }^{11}$ The photothermal induction by NIR irradiation has a great potential for future photodynamic therapy, considering that NIR irradiation in the $800-1100 \mathrm{~nm}$ region can penetrate deeper in tissues and cause less photodamage in comparison to UV-vis irradiation. ${ }^{12}$ However, at this point, there are only few systems of functionalized bio-nanomaterials available that can absorb energy in the NIR region. ${ }^{9}$ In this work, we utilized gold nanorods as a novel triggering system for photothermal induction. Specifically, gold nanorods have been found to exhibit strong surface plasma absorption in the NIR to IR region depending on their aspect ratios. ${ }^{13}$ In addition, the chemical modification on the gold nanorod surface can be easily achieved compared to the surfaces of metal oxide nanomaterial. ${ }^{14}$ Moreover, gold nanorods undergo shape transformation to spherical nanoparticles (nanospheres), ${ }^{15}$ after the absorption of NIR to IR photons. This unique feature may subsequently affect the binding of biomolecules conjugated to the nanorod surface, and be used as a controlled release system of biomolecules. ${ }^{16}$ Furthermore, the cytotoxicity of gold nanomaterials is known

(8) Hamad-Schifferll, K.; Scheartz, J. J.; Santos, A. T.; Zhang, S.; Jacobson, J. M. Nature 2002, 415, 152-155.

(9) (a) Hirch, L. R.; Stafford, R. J.; Bankson, J. A.; Sershen, S. R.; Rivera, B.; Price, R. E.; Hazle, J. D.; Halas, N. J.; West, J. L.Proc. Natl. Acad. Sci. U.S.A. 2003, 100, 13549-13554. (b) Loo, C.; Lin, A.; Hirsch, L. R.; Lee, M. H.; Barton, J.; Halas, N.; West, J.; Drezek, R. Technol. Cancer Res. Treat. 2004, 3, 33-40.

(10) Radt, B.; Smith, T. A.; Caruso, F. Adv. Mater. 2004, 16, 2184-2189.

(11) Shum, P.; Kim, J. M.; Thompson, D. H. Adv. Drug Del. Rev. 2001, 53 $273-284$.

(12) (a) Weissleder, R. Nat. Biotechnol. 2001, 19, 316-317. (b) Vogel, A.; Venugopalan, V. Chem. Rev. 2003, 103, 577-644. (c) Becker, A. Hessenius, C.; Licha, K.; Ebert, B.; Sukowski, U.; Semmler, W.; Wiedenmann, B.; Grotzonger, C. Nat. Biotechnol. 2001, 19, 327-331.

(13) (a) Sau, T. K.; Murphy, C. J. Langmuir 2004, 20, 6414-6420. (b) Nikoobakht, B.; El-sayed, M. A. Chem. Mater. 2003, 15, 1957-1962. (c) Jana, N. R.; Gearheart, L.; Murphy, C. J. J. Phys. Chem. B 2001, 105, 4065-4067. (d) Yu, Y.-Y.; Chang, S.-S.; Lee, C.-L.; Wang, C. R. C. J. Phys. Chem. B 1997, 101, 6661-6664. (e) Jana, N. R.; Gearheart, L.; Murphy, C. J. Adv. Mater. 2001, 13, 1389-1393. (f) Link, S.; El-Sayed, M. A. J. Phys. Chem. B 1999, 103, 8410-8426. (g) Link, S.; El-Sayed, M. A. Int. Rev. Phys. Chem. 2000, 19, 409-433. (h) Kim, F.; Song, J. H.; Yang, P. J. Am. Chem. Soc. 2002, 124, 14316-14317. (a) Link, S.; Mohamed, M. B.; El-Sayed, M. A. J. Phys. Chem. B 1999, 103, 30733077 .

(14) (a) Hayat, M. A. Colloidal Gold: Principles, Methods and Applications Academic Press: New York, 1989. (b) Ulman, A. Chem. Rev. 1996, 96 , 1533-1554. (c) Kreuter, J. In Microcapsules and Nanoparticles in Medicine and Pharmacy; Donbrow, M., Ed.; CRC: Boca Raton, 1992.

(15) (a) Chang, S. S.; Shih, C. W.; Chen, C. D.; Lai, W. C.; Wang, C. R. C. Langmuir 1999, 15, 701-709. (b) Link, S.; Wang, Z. L.; El-Sayed, M. A. J. Phys. Chem. B 2000, 104, 7867-7870.

(16) Takahashi, H.; Niidome, Y.; Yamada, S. Chem. Commun. 2005, 22472249 .
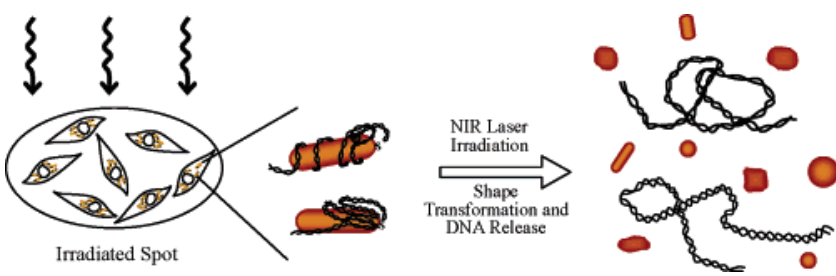

Figure 1. Schematic illustration to demonstrate that the cells containing EGFP-GNR conjugates within a spot $(3.5 \mathrm{~mm}$ in diameter) are irradiated by NIR laser (left). After laser irradiation, the gold nanorods of EGFPGNR conjugates undergo shape transformation that resulted in the release of EGFP DNA (right).

to be lower than that of other nanomaterials such as semiconductors and metal oxide. ${ }^{17}$

In this work, we prepared nanomaterial conjugates composed of EGFP DNA conjugated gold nanorod (EGFP-GNR conjugates). To characterize the effects of NIR irradiation, UV-vis spectroscopy, electrophoresis, and transmission electron microscopy were used to reveal the optical and structural properties of the conjugates before and after laser treatment. We found that when the conjugates were exposed to femto-second NIR irradiation, gold nanorods of EGFP-GNR conjugates changed their shapes and sizes, and released DNA. As shown in Figure 1, after EGFP-GNR conjugates were introduced into HeLa cells and irradiated with the NIR source at the dose that did not cause significant lethality, GFP expression were specifically observed in areas locally exposed to laser irradiation. These results show that EGFP-GNR conjugates combined with NIR irradiation allow the induction of gene expression in specific cells.

\section{Experimental Section}

Materials. Cetyltrimethylammonium bromide (CTAB, 99+\%) and L-ascorbic acid (99\%) were purchased from Acros, and sodium borohydride $(96 \%)$ was purchased from Fluka. Streptavidin-Alexa Fluor 647 Conjugate $(2 \mathrm{mg} / \mathrm{mL}$, Molecular Probes) and EZ-Link sulfo-NHS-SS-biotin (100 mg, Pierce) were used for the preparation of fluorescent DNA-GNR conjugates. Plasmid DNA of enhanced green fluorescent protein (pEGFPN1) was transformed to DH5 $\alpha$ Escherichia coli and purified using Mini-M plasmid DNA extraction system (Virogene Biotek Corp). The primers (MD Bio, Inc.) to amplify the EGFP gene in polymerase chain reaction (PCR) were designed as following: sense primer: 5'-CGC CTT AAG ATA CAT TGA TGA GTT TGG-3'; antisense primer: 5'-HS-CCC CTG ATT CTG TGG ATA ACC G-3'; a thiol group is located at the $5^{\prime}$ end of the antisense primer.

Synthesis of Gold Nanorods. Water-soluble gold nanorods were synthesized via seed-mediated growth routes according to the literatures. ${ }^{13 a, b, c}$ First, the seed solution was prepared as follows: $1 \mathrm{~mL}$ of $\mathrm{CTAB}$ solution $(0.2 \mathrm{M})$ was mixed with 1 $\mathrm{mL}$ of $\mathrm{HAuCl}_{4}(0.0005 \mathrm{M})$. While the solution was stirred at $25^{\circ} \mathrm{C}, 0.12 \mathrm{~mL}$ of ice-cold $0.01 \mathrm{M} \mathrm{NaBH}_{4}$ was added, and the resulting seed solution turned to brownish yellow color. Second, the growth solution was synthesized as follows: $50 \mathrm{~mL}$ of $\mathrm{HAuCl}_{4}(0.001 \mathrm{M}), 50 \mathrm{~mL}$ of CTAB $(0.2 \mathrm{M})$ and $2.5 \mathrm{~mL}$ of $\mathrm{AgNO}_{3}(0.004 \mathrm{M})$ were mixed at $25^{\circ} \mathrm{C}$. After gentle mixing of the solution, $670 \mu \mathrm{L}$ of ascorbic acid $(0.079 \mathrm{M})$ was added to

(17) (a) Connor, E. E.; Mwamuka, J.; Gole, A.; Murphy, C. J.; Wyatt, M. D. Small 2005, 1, 325-327. (b) Colvin, V. L. Nat. Biotechnol. 2003, 21, 11661170 
the solution, and the solution color changed from dark yellow to colorless. To generate nanorods, $120 \mu \mathrm{L}$ of the seed solution was added to the growth solution at $27-30{ }^{\circ} \mathrm{C}$ under gently mixing. Within 10-20 min, the combined solution gradually changed colors to brownish red. The solution was then centrifuged to remove the excessive CTAB. Finally, the nanorod sample was characterized by the transmission electron microscope (TEM, Hitachi H-7100) and UV-vis-NIR spectrometer (HP-8453 and Perkin-Elmer: $\lambda$-900).

Preparation of DNA and Gold Nanorod Conjugates. The pEGFP-N1 was used as the template DNA. The PCR program were set as following: step 1: $95^{\circ} \mathrm{C}$ for $5 \mathrm{~min}$; step 2: $95{ }^{\circ} \mathrm{C}$ for $0.5 \mathrm{~min}, 50{ }^{\circ} \mathrm{C}$ for $1 \mathrm{~min}, 72^{\circ} \mathrm{C}$ for $2 \mathrm{~min}, 60$ cycles; step 3: $72{ }^{\circ} \mathrm{C}$ for $10 \mathrm{~min}$. A large amount of thiolated EGFP DNA (DNA-SH) was amplified by PCR and stored at $-20^{\circ} \mathrm{C}$. The size of amplified DNA was confirmed by agarose gel electrophoresis.

The DNA-SH $(54 \mu \mathrm{g}, 25 \mu \mathrm{L})$ sample was added drop by drop into the gold nanorod solution $(1 \mathrm{mg}, 15 \mathrm{~mL})$. The approximate molecular ratio of DNA-SH and gold nanorods was adjusted to be $1.5: 1$ for the conjugating reaction. ${ }^{18}$ The solution was then shaken for $96 \mathrm{~h}$ at room temperature. Finally, the resulting solution was centrifuged at $5000 \mathrm{rpm}$ for $20 \mathrm{~min}$ and then the supernatant was decanted to remove unbound DNA-SH. The EGFP-GNR conjugate precipitate was collected for the further characterization and transfection experiments described below.

Shape Transformation of EGFP-GNR Conjugates Using Femtosecond NIR Laser Irradiation. The femtosecond laser system consists of a $82 \mathrm{MHz}$ mode-locked Ti:sapphire oscillator (Tsunami, Spectra-Physics) and a $1 \mathrm{kHz}$ Ti:sapphire regenerative amplifier (Spitfire, Spectra-Physics) pumped by a $1 \mathrm{kHz}$ Q-switched Nd:YLF laser (Merlin, Spectra-Physics). The $80 \mathrm{fs}$ pulse from oscillator was amplified in chirped-pulse regenerative amplifier, producing $130 \mathrm{fs}$ pulse with $1 \mathrm{~mJ}$ of pulse energy at $800 \mathrm{~nm}$. The laser beam with $110 \mu \mathrm{J} /$ pulse energy $\left(1.14 \mathrm{~W} / \mathrm{cm}^{2}\right)$ was split out and narrowed to a spot size of about $3.5 \mathrm{~mm}$ to perform the following experiments. Neutral density filters were employed to vary the laser energy.

The laser pulses with $0,48,62,79$, and $108 \mu \mathrm{J}$ at $800 \mathrm{~nm}$ were separately applied onto individual EGFP-GNR conjugate solutions for $0,30,60,120$, and $240 \mathrm{~s}$. The absorption spectrum of each solution was recorded after irradiation. The shape transformation of gold nanorods was confirmed by TEM measurements.

Fluorescent EGFP-GNR Conjugates in Living Cells. Aqueous EZ-Link sulfo-NHS-SS-biotin (1 mL, $10 \mathrm{mM})$ was mixed with EGFP-GNR conjugate solution $(\sim 0.5 \mathrm{mg}, 9 \mathrm{~mL})$ for $1-2 \mathrm{~h}$ to form gold-thiol bond. The resultant solution was then added with $35 \mu \mathrm{L}$ of fluorescent probe solution $(1 \mathrm{mg} /$ mL, Streptavidin-Alexa Fluor 647 Conjugate) and gently vortexed at room-temperature overnight. Afterward, the solution was centrifuged at $5000 \mathrm{rpm}$ for $20 \mathrm{~min}$. The suspension was removed, and the precipitate was kept to be introduced into the HeLa cells. After $3 \mathrm{~h}$, the HeLa cells were twice washed by PBS and imaged by laser-scanning confocal microscopy (Lecia, TCS SP2).

Cell Viability Assays after EGFP-GNR Transfection and NIR Irradiation. HeLa cells were cultured on separated dishes

(18) The molecular weight $\left(3.1 \times 10^{7}\right)$ of a gold nanorod is estimated based on its total volume $\left(\sim 5 \times 10^{3} \mathrm{~nm}^{3}\right)$ and density $\left(31 \mathrm{Au} / \mathrm{nm}^{3}\right)$ and then each fed with $25 \mu \mathrm{L}$ of $\mathrm{CaCl}_{2}(2.5 \mathrm{M})$ and EGFPGNR conjugate solution $(\sim 1 \mathrm{mg}, 225 \mu \mathrm{L})$. After $6 \mathrm{~h}$ of incubation at $37{ }^{\circ} \mathrm{C}$ in a $\mathrm{CO}_{2}$ incubator, the cells on each dish was marked with seven $3.5 \mathrm{~mm}$ spots, intended for NIR laser exposure. Two different cell viability assays were performed. The first set of the samples ( 6 dishes) were exposed to the laser with different energy dose of $0,48,62,79,88$, and $108 \mu \mathrm{J} /$ pulse for $1 \mathrm{~min}$. The second set of the samples ( 5 dishes) were exposed to the laser with $79 \mu \mathrm{J} /$ pulse for $0,1,3,5$, and $7 \mathrm{~min}$ separately. After irradiation, the cells in each dish were cultured with fresh Dulbecco's Modified Eagle Medium (DMEM) for an additional $6 \mathrm{~h}$ for the trypan blue exclusion staining assay. In the assay, attached HeLa cells were washed with PBS and then added with $0.4 \%$ trypan blue (Sigma). The percentage of viable cells within laser treated area $(3.5 \mathrm{~mm}$ in diameter) was calculated from the ratio of the number of viable cells divided by total number of cells.

EGFP Expression in Living Cells Transfected with EGFPGNR Conjugates after NIR Irradiation. HeLa cells were cultured in DMEM with $10 \%$ fetal calf serum (FCS) in the presence of $1 \%$ penicillin and streptomycin. The cells were grown at $37{ }^{\circ} \mathrm{C}$ in a $\mathrm{CO}_{2}$ incubator and passed every 2 days. For transfection experiments, the HeLa cells were seeded on dishes and cultured for $16 \mathrm{~h}$. The cells in $5 \mathrm{~mL}$ of DMEM were fed with the mixture of $\mathrm{CaCl}_{2}(25 \mu \mathrm{L}, 2.5 \mathrm{M})$ and EGFP-GNR conjugate solution $(\sim 1 \mathrm{mg}, 225 \mu \mathrm{L})$. After $6 \mathrm{~h}$ incubation at $37{ }^{\circ} \mathrm{C}$ in a $\mathrm{CO}_{2}$ incubator, the residual conjugates in the solution were removed by washing with PBS and replaced with fresh serum containing DMEM. The culture dishes were marked with five spots (3.5 $\mathrm{mm}$ in diameter). Each spot was exposed to NIR laser (79 $\mu \mathrm{J} /$ pulse) for $1 \mathrm{~min}$. The cells were then incubated for 48 h. Finally, the cells were washed with PBS and observed with under epifluorescence or laser-scanning confocal microscopy.

\section{Result and Discussion}

Gold nanorods with aspect ratio of $\sim 3.8$ were attached to EGFP DNA to prepare EGFP-GNR conjugates. Before the conjugation reaction, the structural and optical properties of gold nanorods were confirmed by TEM and UV-vis spectroscopy. The resulting conjugates showed very good water solubility without precipitation or aggregation in water-based solutions. The high solubility may be attributed to the attached DNA and/ or residual CTAB remained on the gold nanorod surface. ${ }^{19}$ In the TEM image (Figure 2), EGFP-GNR conjugates were welldispersed on an amorphous carbon grid with a narrow size distribution $( \pm 7 \%)$. The averaged aspect ratio of gold nanorods of the conjugates was calculated to be $\sim 3.8$ (length/diameter $=\sim 42 / 11$ in $\mathrm{nm}$ ), consistent with that of free gold nanorods without DNA attachment. The UV-vis absorption spectra showed that the surface plasma band from the gold nanorods of EGFP-GNR conjugates remained in the same position as free gold nanorods, even after the conjugates were kept at the room temperature for more than two weeks. These results indicated that after DNA attachment, the morphology (aspect ratio) of gold nanorods did not change and the aggregation of gold nanorods did not occur.

(19) Gole, A.; Murphy, C. J. Chem. Mater. 2005, 17, 1325-1330. 


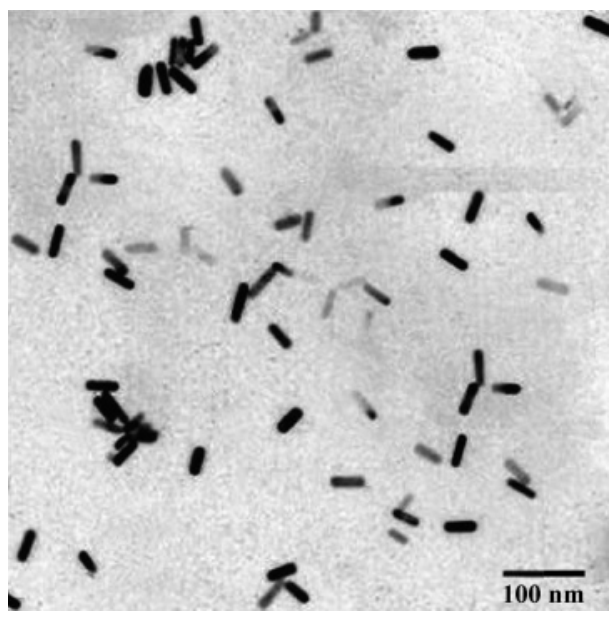

Figure 2. Representative TEM image of dispersive EGFP-GNR conjugates. The rodlike structures are gold nanorods.
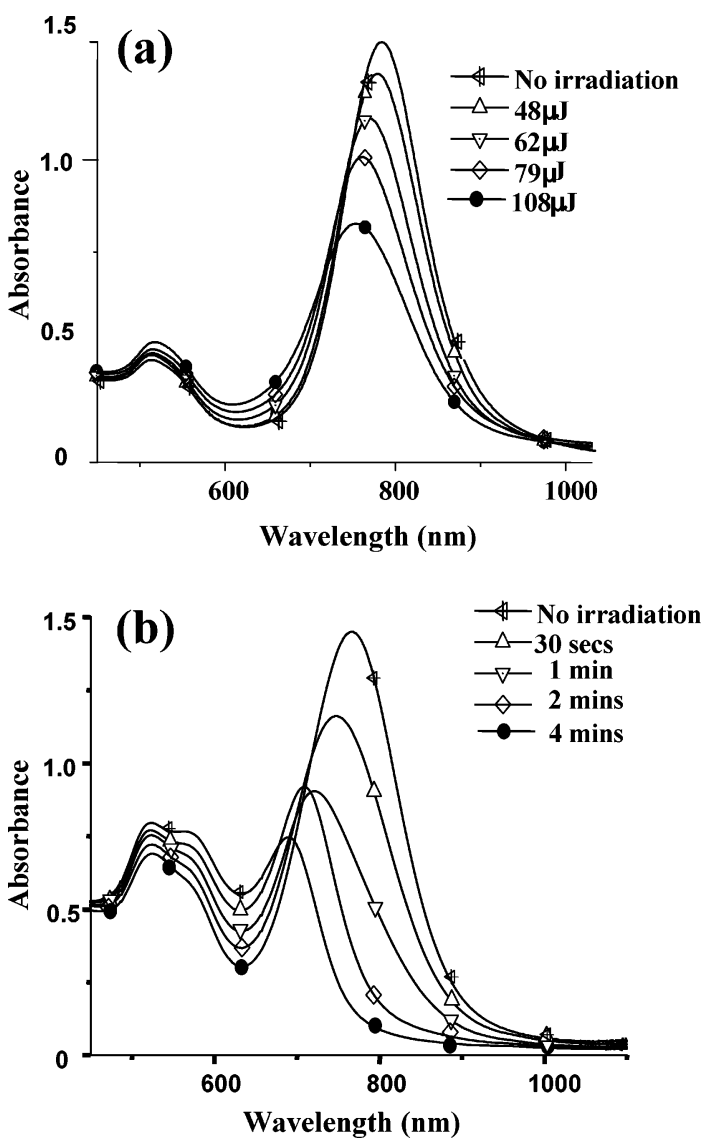

Figure 3. (a) The UV-vis spectra of EGFP-GNR conjugates before and after irradiation at different energy doses of the laser pulse (beam size with $3.5 \mathrm{~mm}$ in diameter and $130 \mathrm{fs}$ pulse energy at $800 \mathrm{~nm}$ ) for $60 \mathrm{~s}$. (b) The UV-vis spectra of EGFP-GNR conjugates before and after irradiation at $108 \mu \mathrm{J} /$ pulse of the laser pulse for different time periods.

Femto-second NIR laser irradiation was applied to induce the shape transformation of gold nanorods in the EGFP-GNR conjugates. The transformation of gold nanorods into spherical nanoparticles (nanospheres) was monitored using UV-vis spectroscopy. Figure 3a showed the UV-vis spectra of the EGFP-GNR conjugates before and after irradiation by a femtosecond NIR laser with different energy doses. Before irradiation, the UV-vis spectrum of the conjugates exhibited clearly two surface plasma absorption bands at $\sim 520$ and $\sim 782$ nm, which corresponds well with that of gold nanorods with the aspect ratio of $\sim 3.8 .{ }^{13}$ The spectra in Figure $3 \mathrm{a}$ and $\mathrm{b}$ show the decrease of the peak intensity at $\sim 782 \mathrm{~nm}$ and the increase at $\sim 520 \mathrm{~nm}$ when NIR irradiation power increases or when total irradiation time increases, indicating that some gold nanorods of the conjugates were transformed into gold nanospheres. ${ }^{15}$ Note that the absorption band at $\sim 520 \mathrm{~nm}$ is a characteristic feature of gold nanospheres. ${ }^{13,20}$ In Figure $3 \mathrm{~b}$, after the irradiation the absorption peak at $\sim 782 \mathrm{~nm}$ was shifted to $691 \mathrm{~nm}$ and the absorption intensity at $\sim 520 \mathrm{~nm}$ significantly increased. The blue shift of the original peak at $\sim 782 \mathrm{~nm}$ suggested that some of gold nanorods were transformed into the nanorods with smaller aspect ratios $(<3.8)$ after the irradiation treatment.

The shape transformations of the nanorods after NIR irradiation were further confirmed by TEM measurements. Figure $4 \mathrm{a}$ and $4 \mathrm{~b}$ showed the TEM images of gold nanorod samples before and after laser irradiation, respectively, indicating a shape change from gold nanorods to nanospheres or nearly spherical nanoparticles. The nanospheres in Figure 4a exhibited a broad shape and size distribution. It is possible that the laser energy transformed a single nanorod into several nanospheres, which might subsequently melt and fuse in solution to generate nearly spherical nanoparticles with various sizes. ${ }^{15,16}$ During shape transformation from gold nanorods to nanospheres or small nanorods, the surface atom rearrangement might induce DNA release from EGFP-GNR conjugates. Agarose gel electrophoresis was applied to examine such a possibility.

Figure 5 showed that free EGFP and the EGFP DNA of EGFP-GNR conjugates migrated to the opposite ends on the gel during electrophoresis. The migration of EGFP-GNR conjugates to the anode indicates the positive charge nature of the conjugates. Free EGFP DNA was detected when EGFPGNR conjugates were subjected to the irradiation treatment. In contrast, with no irradiation the release of EGFP DNA from EGFP-GNR conjugates was not detected. Therefore, irradiation serves as a trigger for DNA release from EGFP-GNR conjugates. The observation that GFP DNA was separated from gold nanorods during electrophoresis supports the notion that most, if not all, released DNA molecules was not re-adsorbed to nanospheres' surfaces. This may be due to oxidation of thiol to sulfonate $\left(-\mathrm{SO}_{3} \mathrm{H}\right){ }^{21}$ The released DNA from EGFP-GNR conjugates exhibited similar mobility as free EGFP DNA, suggesting that DNA is of similar size and weight after irradiation. On the basis of the band intensity before and after irradiation, approximately $70 \pm 15 \%$ of DNA was released from conjugates and separated from the nanorods on the gel during electrophoresis. In addition, EGFP-GNR conjugates exhibited a single band on the gel, indicating that the size of the conjugates and the number of DNA molecules attached to the conjugates were quite uniform. Finally, the positive charge nature of EGFP-GNR conjugates might be caused by the residual CTAB remained on the gold nanorod surface. ${ }^{19}$

The detachment of DNA from EGFP-GNR conjugates likely results from the breakage of $\mathrm{Au}-\mathrm{S}$ bond between the nanorod

(20) The increases of the peak intensity at $\sim 565 \mathrm{~nm}$ in Figure $3 \mathrm{~b}$ is possibly due to the absorption of irregular-shaped gold nanoparticles and/or the aggregation of small gold nanoparticles when the total irradiation time increases.

(21) Huang, J.; Dahlgren, D. A.; Hemminger, J. C. Langmuir 1994, 10, 626628 . 

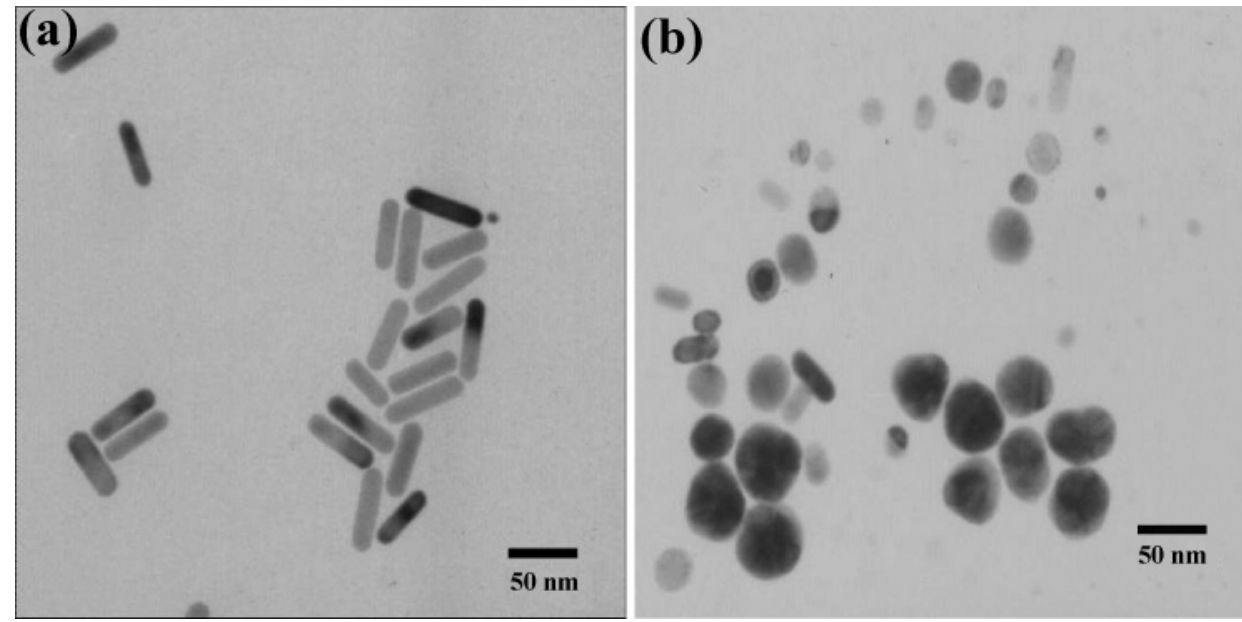

Figure 4. Typical TEM images of EGFP-GNR conjugates (a) before and (b) after irradiation with laser beam (79 $\mu \mathrm{J} / \mathrm{pulse}$ for $60 \mathrm{~s})$.

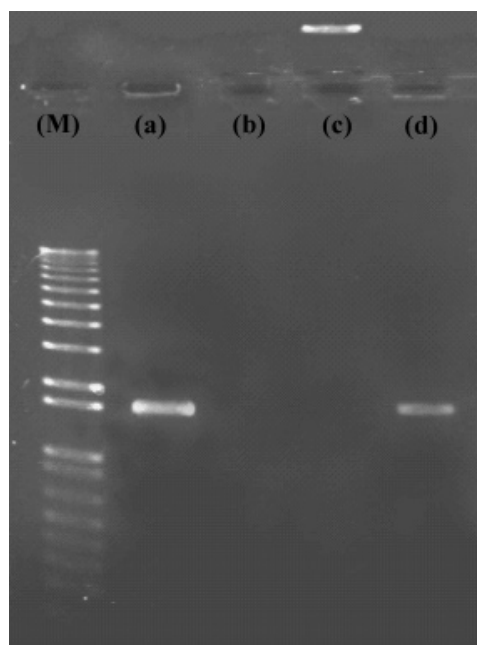

Figure 5. Gel electrophoresis $(0.7 \%$ agarose gel at $110 \mathrm{~V} / \mathrm{cm}, 1 \times \mathrm{TBE}$ $0.5-1.0 \mathrm{~h}$ ) was used to confirm DNA release upon irradiation. The samples loaded on the gel are (M) DNA molecular weight reference standard, (a) free EGFP DNA, (b) free gold nanorods, (c) EGFP-GNR conjugates before and (d) after NIR laser irradiation ( $79 \mu \mathrm{J} /$ pulse at $800 \mathrm{~nm}$ for $1 \mathrm{~min})$.

surface and EGFP DNA during the irradiation-induced atomic rearrangement process. Two possible kinetic mechanisms, thermal and electron heating, are proposed to explain the bond breakage. Local heating by laser energy absorption may raise the temperature of nanorods ${ }^{22}$ and breaks $\mathrm{Au}-\mathrm{S}$ bond through thermal energy transfer. Also, it is possible that laser irradiation may instantaneously increase the temperature of free electrons (so-called hot electrons) in gold nanorods and, as a consequence, may result in $\mathrm{Au}-\mathrm{S}$ bond breakage through strong electronmolecule interaction. This electron-mediated dissociation channel has been well studied on surface chemistry of metals and might be more efficient than the heat-mediated dissociation channel. ${ }^{23}$ Our experimental results (estimation based on UVvis spectroscopy and electrophoresis measurements) indicated that the percentage of shape transformation of the nanorods was less than that of the DNA release from the nanorods under the femto-second laser irradiation at the same power. Therefore,

(22) Chou, C.-H.; Chen, C. D.; Wang, C. R. C. J. Phys. Chem. B 2005, 109, $11135-11138$.

(23) Huang, J. Y.; Shen, Y. R. In Laser Spectroscopy Photochemistry on Metal Surfaces; Dai, H. L., Ho, W., Eds; World Scientific: Singapore, 1995.

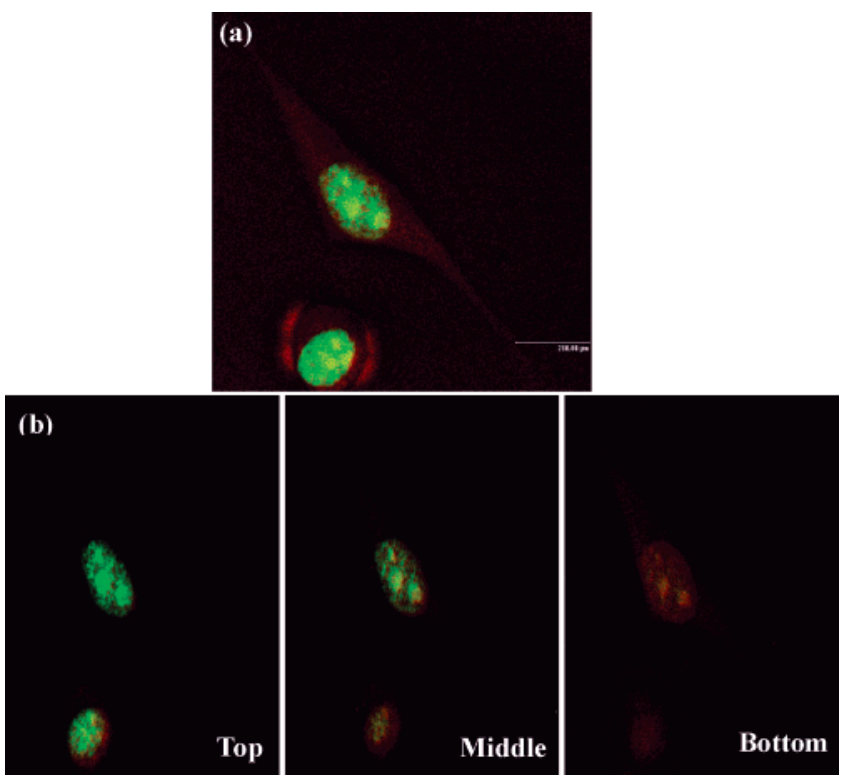

Figure 6. (a) A representative confocal microscopic image of fluorescent EGFP-GNR conjugates in the cells. EGFP-GNR conjugates were labeled red and the nucleus was stained green by syto 11 . (b) Three confocal images recorded at different focal planes (top, middle, and bottom of cells) to show that the conjugates indeed enter the cells.

we suggested that the electron-mediated channel may play an important role for the photodissociation reaction.

We further investigated if the induced release of EGFP DNA from EGFP-GNR conjugates by irradiation may be utilized in living cells as a nonchemical or nonviral inducible system for gene expression. We first tested whether EGFP-GNR conjugates could enter living cells. To monitor EGFP-GNR conjugates in cells, we added a fluorescent probe on their surface and incubated the fluorescent conjugates with HeLa cells. The fluorescent conjugates were first detected within the cells after approximately $1 \mathrm{~h}$ incubation. Three hours later, a significant amount of the conjugates were found inside the cells. Figure 6 showed a representative confocal microscopic image of fluorescent EGFP-GNR conjugates in the cells. The conjugates were distributed in the cytoplasm based on serial $\mathrm{Z}$ cross-section microscopic images. These conjugates may enter cells through endocytosis as the bio-conjugates consisting of quantum dots or carbon nanotubes have been also shown to enter mammalian cells through endocytosis. . $^{3,6}$ 


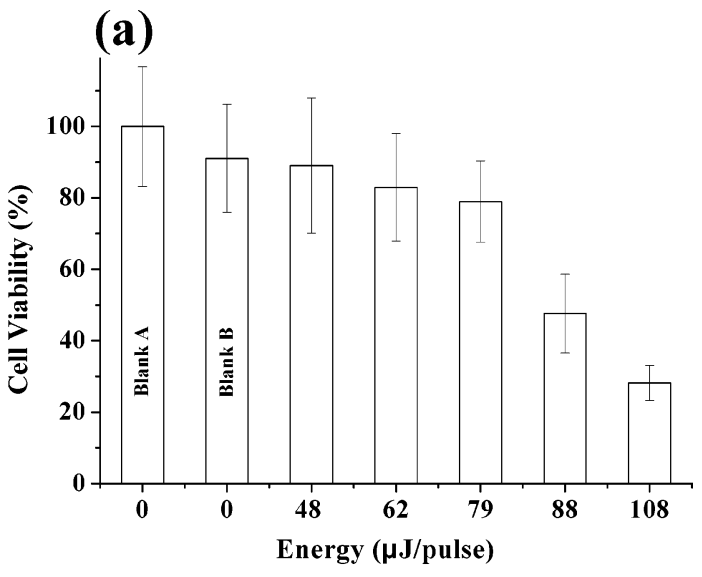

(b)

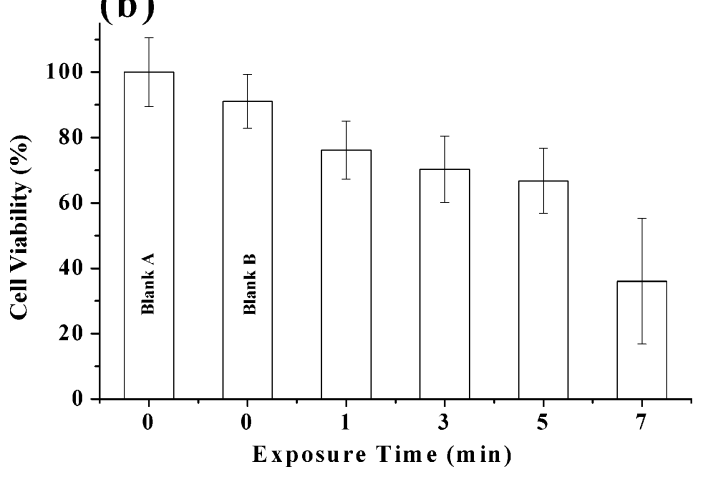

Figure 7. Viability assay of cells treated with EGFP-GNR conjugates and irradiated with NIR at different doses. (a) A plot of the irradiation energy versus cell vitality after 1 min NIR laser irradiation. (b) A plot of the irradiation time versus cell vitality after irradiation with $79 \mu \mathrm{J} /$ pulse of NIR laser. Cell vitality was examined by the trypan blue assay. The blank A in both plots were from HeLa cells without the EGFP-GNR conjugates and irradiation treatment. The blank B in both plots were from HeLa cells incubated with EGFP-GNR conjugates but without NIR laser irradiation.

To obtain an optimal NIR irradiation dose for living cells, we examined the effect of various irradiation doses on cell viability (Figure 7). As a control, without irradiation, 90\% of the cells incubated with the EGFP-GNR conjugates for $12 \mathrm{~h}$ remained vital. The low percentage $(10 \%)$ of cell death could be due to free CTAB surfactant ${ }^{17 a, 19}$ or oxidized gold salt. When irradiated with $79 \mu \mathrm{J} /$ pulse laser for $1 \mathrm{~min}, \sim 80 \%$ of the cells were still vital. Such an irradiation dose was sufficient to induce shape transformation of gold nanorods and the subsequent release DNA from EGFP-GNR conjugates as described above. When exposed to irradiation of $88 \mu \mathrm{J} /$ pulse laser for $1 \mathrm{~min}$ (or $79 \mu \mathrm{J} /$ pulse for $7 \mathrm{~min}$ as shown in Figure 7 ), more than $50 \%$ of cell death was observed. The cell death was likely attributed to the heating effect from gold nanorods inside the cells, as the photon energy absorbed by nanorods may increase local temperature rapidly. ${ }^{22}$ We therefore used the irradiation condition of $79 \mu \mathrm{J} /$ pulse laser for $1 \mathrm{~min}$, which did not cause significant cell death and is sufficient to trigger the release of EGFP DNA from EGFP-GNR conjugates.

We then applied NIR irradiation to cells treated with EGFPGNR conjugates and evaluated the release and expression of EGFP in the irradiated cells directly by a confocal microscope (Figure 8). Only irradiated spots showed strong GFP expression 1-2 days after NIR exposure. No gene expression was observed outside the irradiated spots. The control experiments using free EGFP DNA without gold nanorods showed no GFP expression

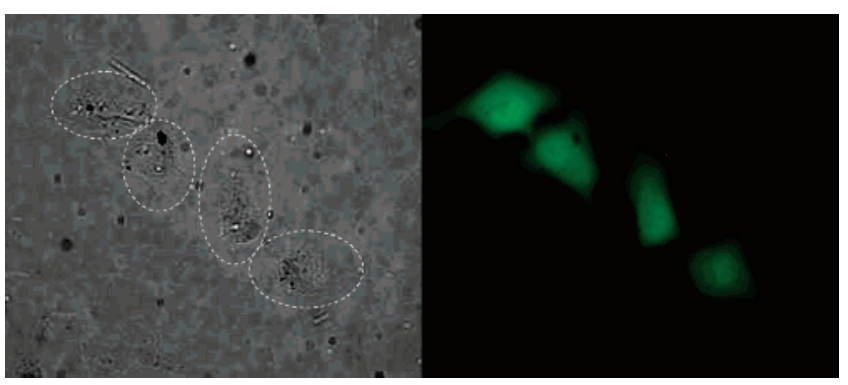

Figure 8. Expression of EGFP in cells incubated with the DNA-GNR conjugates. (a) The bright-field image of cells (white circles) incubated with the conjugates after the laser irradiation. (b) The confocal image of the same cells showing GFP expression.

under the condition either with or without NIR laser irradiation. These results indicated that EGFP-GNR conjugates entered cells and that localized release of EGFP DNA and subsequent GFP expression can be triggered by NIR laser irradiation to specific cells in the culture dish.

Interestingly, when the EGFP plasmid without a thiol group was conjugated with gold nanorods, expression of fluorescent protein was readily observed in the cells fed with the conjugate, even without NIR irradiation. This observation is consistent with the previous report that the conjugate formed by mixing GFP DNA (without a thiol group) and gold nanoparticles, ${ }^{2 a, h, 4 b}$ when delivered to mammalian cells, can cause GFP expression. The negatively charged EGFP and positively charged gold nanorods (likely due to the residual CTAB surfactant remained on the gold nanorod surface) may form a conjugate through electrostatic attraction. When the conjugate entered cells, at least, some EGFP DNA may be dissociated from the conjugates and underwent expression. In contrast, as described above, only when irradiated with NIR was GFP expression observed in cells fed with the gold nanorod conjugated with the EGFP DNA with a thiol group. The optical inducibility of gene expression in the latter is likely due to the predominant and stronger $\mathrm{Au}-\mathrm{S}$ bond rather than the minor and weaker electrostatic interaction between DNA and the gold nanoparticle surface.

Gene delivery with a relatively high transfection rate has been achieved using virus system as a delivery carrier. ${ }^{24}$ As viral systems likely cause unexpected cytotoxicity and immunogenicity after delivery, many nonviral delivery systems such as lipids, dendrimers, and polyethylamine have been developed as gene carriers. ${ }^{25}$ Although the transfection rate using gold nanorods as a carrier is not very high $(<20 \%)$ at the present stage; our method provides a controllable system to turn on localized gene expression without causing significant cytotoxicity or immunogenicity. More importantly, NIR is more penetrable in and less harmful to cells and tissues of animals than other irradiation sources. ${ }^{12}$ Therefore, it allows selective induction of gene expression in specific cells of internal tissues or organs. This gene expression system combining DNA-GNR conjugates with NIR irradiation is expected to be useful in the temporal and spatial induction of gene expression at cellular and organismal levels.

(24) Verma, I. M.; Somia, N. Nature 1997, 389, 239-242.

(25) (a) Gonzalez, H.; Hwang, S. J.; Davis, M. E. Bioconjugate Chem. 1999 10, 1068-1074. (b) Boussif, O.; Lezoualc'h, F.; Zanata, M. A.; Mergny, M. D.; Scherman, D.; Demeneix, B.; Behr, J. P. Proc. Natl. Acad. Sci. USA 1995, 92, 7297-7301. (c) Ruponen, M.; Ya-Herttuala, S.; Urtti, A. Biochim. Biophys. Acta 1999, 1415, 331-341. (d) Boulikas, T.; Martin, F. Int. J. Oncol. 1997, 10, 317-322. 
In conclusion, we have prepared a new nanomaterial conjugate combining gold nanorod and EGFP DNA. Upon femtosecond NIR irradiation, the gold nanorods of EGFP-GNR conjugates underwent shape change and released EGFP DNA. When the conjugates were delivered to cultured HeLa cells, induced GFP expression was observed in the localized area exposed to NIR irradiation. Our results demonstrate the use of DNA-GNR conjugates for remote control of local gene expression and its potential application in biological and medical studies.

Acknowledgment. We acknowledge financial supports from the NSC, NSTP, Ministry of Education, Academia Sinica, NHRI and NTNU and technical supports from Profs. C. R. C. Wang, J.-K. Wang, and Y.-C. Wang.

JA0570180 